BRE 20357

\title{
Hippocampal kindling: corticosterone modulation of induced seizures
}

\author{
G. A. COTTRELL ${ }^{1}$, C. NYAKAS ${ }^{1}$, E. R. DE KLOET ${ }^{1}$ and B. BOHUS ${ }^{2, *}$ \\ 'Rudolf Magnus Institute for Pharmacology, University of Utrecht, 3521 GD Utrecht and 2Department of Animal Physiology, \\ University of Groningen, P.O. Box 14, 9750 AA Haren (The Netherlands)
}

(Accepted May 8th, 1984)

Key words: kindling — hippocampus - adrenalectomy - corticosterone — behavioral depression — after-discharge

\begin{abstract}
The effect of adrenalectomy (ADX) and corticosterone replacement was studied on seizures induced by hippocampal kindling. A complex series of changes occurred in after-discharge (AD) and behavioural depression (BD) during the immediate hours after ADX, culminating at day 1 in markedly decreased $\mathrm{AD}$ and $\mathrm{BD}$, which returned to normal over the next several days. These changes were normalized after replacement of the ADX group with low doses of corticosterone. It is concluded that the expression and maintenance of hippocampal kindled seizures is under short-term control of corticosterone.
\end{abstract}

Certain corticosteroid increase an animal's susceptibility to seizures and lower the convulsive threshold in animal and man $9.16,17$. Endröczi ${ }^{5}$, Halmi et al. ${ }^{8}$ and Feldman ${ }^{6}$ showed that the hippocampus is implicated in this hormone action. The hippocampus is an important target for corticosterone, and the hippocampal neurone contains a large number of receptor sites specific for this naturally occurring glucocorticoid of the rat ${ }^{2,11,12,15}$. We were interested in specifying the physiological role of the adrenal hormonal system in the excitability of the hippocampus as studied on established hippocampal-induced seizure behaviour.

The kindling method ${ }^{7}$ was used to produce reliable and repeatable seizures from the hippocampus. The role of the adrenals was investigated using a classical endocrine approach: kindling induced after-discharge (AD) and behavioural depression (BD) were disturbed up to two days following removal of endogenous corticosteroids by adrenalectomy (ADX), and restored after substitution of the ADX rat with exogenous corticosterone.

Ninety-three male Wistar rats bred in the Rudolf Magnus Institute were used in this study. The rats were anaesthetized with Nembutal or Hypnorm and implanted bilaterally with bipolar electrodes made of twisted, teflon-coated, stainless-steel wire $(0.15 \mathrm{~mm})$ in the dorsal hippocampus. A stainless-steel wire $(0.15 \mathrm{~mm})$ was implanted in the neck muscle to serve as a ground. The rats were kindled, the current threshold for reliable seizures determined, they were first used in another experiment involving peptide treatment ${ }^{3}$. Kindling was then maintained with daily threshold current for 1-2 weeks before the start of the present experiment. At this time, the animals had been given regular kindling sessions for 4-6 months and weighed $500-600 \mathrm{~g}$.

Behavioural measurements and electroencephalographic (EEG) recordings were made during each test session. The EEG was continuously recorded through one hippocampal electrode on a Grass model $79 \mathrm{C}$ polygraph/electroencephalograph. The rat was stimulated through the contralateral electrode (1-s train, $1 \mathrm{~ms}$ pulses, $60 \mathrm{~Hz}$, individual current intensity). The duration of the $\mathrm{BD}$ (defined as the whole period of behavioural disturbance, i.e. tonicchloric seizures, behavioural arrest, etc.), until the animal started moving around the test cage again was recorded. The duration of the AD, i.e. the period of synchronous bursting electrical activity, was measured from the EEG record.

Correspondence: B. Bohus, Department of Animal Physiology, University of Groningen, P.O. Box 14, 9750 AA Haren, The Netherlands. 
Electrode sites were verified as being within the anterior dorsal hippocampus, with the majority located about $2.5 \mathrm{~mm}$ lateral to the midline at the level of the hippocampal fissure, upper blade of the dentate gyrus and CA4.

Experiment 1 involved three series of observations. The rats were adrenalectomized (ADX) or sham-operated either $1 \mathrm{~h}$ (Experiment $1 \mathrm{~A}), 4 \mathrm{~h}$ (Experiment $1 \mathrm{~B}$ ) or $8 \mathrm{~h}$ (Experiment $1 \mathrm{C}$ ) before the kindling session. Bilateral ADX was performed under ether anaesthesia. Kindling sessions were continued every day for 5 or 14 days.

Difference scores were analyzed by an SPSS MANOVA computer program for repeated measures ${ }^{10}$. The difference score was the duration of the $\mathrm{AD}$ or BD following operation and/or treatment minus preintervention baseline value for each rat. Three animals were discarded from the analysis due to incomplete data. The results from the three series of observations in Experiment 1 are presented in Fig. 1.

Experiment $1 A$. At $1 \mathrm{~h}$ post-ADX or sham-operation, the percentage of animals having seizures was reduced in both ADX (11\%) and sham (25\%) groups. The duration of the $\mathrm{AD}$ and $\mathrm{BD}$ was significantly reduced in both groups (AD, $t=-5.315, P<$ $0.0001 ; \mathrm{BD}, t=-5.173, P<0.0001)$ as compared to pre-operative measures, but the $\mathrm{AD}$ and $\mathrm{BD}$ in the two groups was not significantly different. However, by one day postoperation the sham groups had returned to pre-operation baseline levels (i.e. were having normal seizures); while in the ADX group the number of seizures $(33 \%)$ and the duration of $A D$ and $\mathrm{BD}$ was still significantly reduced $(\mathrm{AD}, t=$ $-3.591, P<0.003$; BD, $t=-2.134, P<0.05$ ). Two days postoperation, the AD was still significantly reduced $(t=-2.908, P<0.011)$, while the BD had returned to pre-ADX baseline levels. On the third day post-ADX, the duration of the AD had returned to normal.

Experiment $1 B$. At $4 \mathrm{~h}$ post-ADX, the ADX group exhibited a significantly longer $\mathrm{BD}(t=2.453, P<$ $0.025)$, but normal AD. At one day post-ADX, the ADX group exhibited significantly decreased $A D$ and BD (AD, $t=-2.798, P<0.012$; BD,$t=-2.094$, $P<0.05$ ). By two days post-ADX, the AD and BD had returned to pre-ADX baseline levels. The shams were normal throughout, i.e. their $\mathrm{AD}$ and $\mathrm{BD}$ were not influenced by the sham operation in comparison to pre-operative levels.

Experiment $1 C$. At $8 \mathrm{~h}$ there appears to be no difference between ADX and sham-operated groups, as
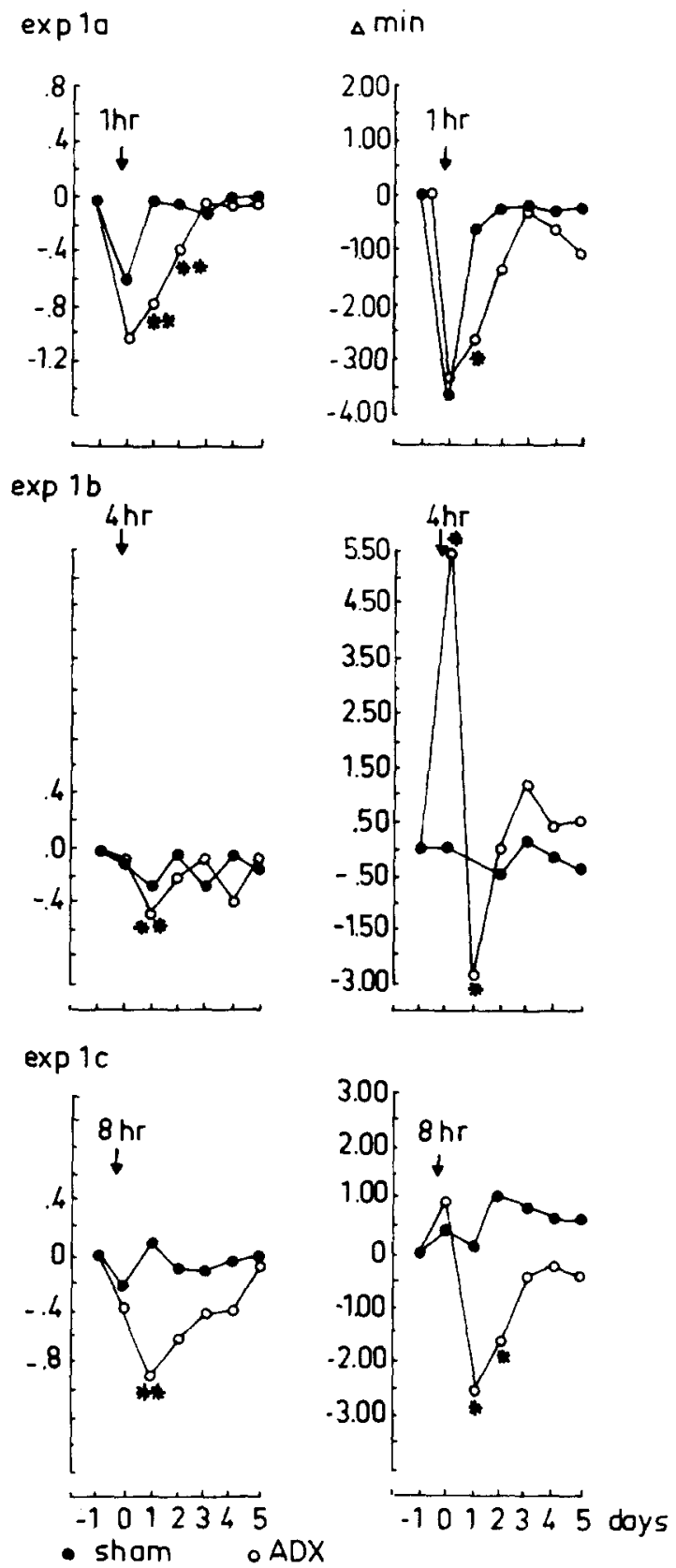

Fig. 1. Effect of 1 (Experiment 1A), 4 (Experiment $1 \mathrm{~B}$ ) or $8 \mathrm{~h}$ (Experiment 1C) adrenalectomy $(\mathrm{O}-\mathrm{O})$ or sham-operation (-) on the duration of the after-discharge (left) and of the behavioural depression (right) in hippocampal kindled rats. The mean difference scores have been plotted as a deviation from pre-operative baseline. There were $7-12$ rats per group. Statistical significance of differences between adrenalectomized and sham-operated rats is shown by asterisks: ${ }^{*} P<0.05 ;{ }^{* *} P<0.01$. 
can be seen in Fig. 1C. However, the mean BD of the ADX group is not representative and is, in reality, composed of a bimodal distribution. Seven rats exhibited the 4-h effect, an increased BD ( $\overline{\mathrm{x}}=3.04)$, while 5 rats showed the one-day effect, decreased $\mathrm{BD}(\overline{\mathrm{x}}=-2.234)$. These two subpopulations are significantly different from each other $(t=4.138, P<$ $0.01)$ and from the sham group $(\mathrm{F}=8.064, P<0.01)$. At one day post-ADX, the ADX group exhibited decreased $\mathrm{AD}$ and $\mathrm{BD}(\mathrm{AD}, t=-2.870, P<0.011$; $\mathrm{BD}, t=-2.079, P<0.05)$. At two days post-ADX, the $\mathrm{AD}$ had returned to normal, but the $\mathrm{BD}$ was still significantly reduced $(t=-2.552, P<0.021)$. By_day 3 post-ADX, the BD had also returned to normal.

All of the above animals were tested until the fifth day postoperation. Twenty-two of them were tested for 14 days. Following the disappearance of the initial effect as described above, the $\mathrm{AD}$ and $\mathrm{BD}$ remained unchanged.

The second series of experiments was designed to investigate whether adrenalectomy-induced alterations were due to the absence of corticosterone. There were three groups in these experiments: sham, ADX and ADX with corticosterone substitution (ADC). The operation was performed $4 \mathrm{~h}$ prior to the kindling session. Corticosterone, $0.5 \mathrm{mg} / \mathrm{kg}$ (in $5 \%$ propylene glycol), was administered subcutaneously at four time points $0,1,2$ and $3 \mathrm{~h}$ post-ADX to the ADC group. This dose regimen had been found, in pilot studies, to produce plasma levels of corticosterone equivalent to physiological levels at the time of kindling. The ADX and sham groups received vehicle injections. All animals received vehicle injections on days preceding and following the operation. Immediately following the kindling session, at $4 \mathrm{~h}$ post-operation, eye-plexus blood was taken un- $\exp 2 \quad A D$

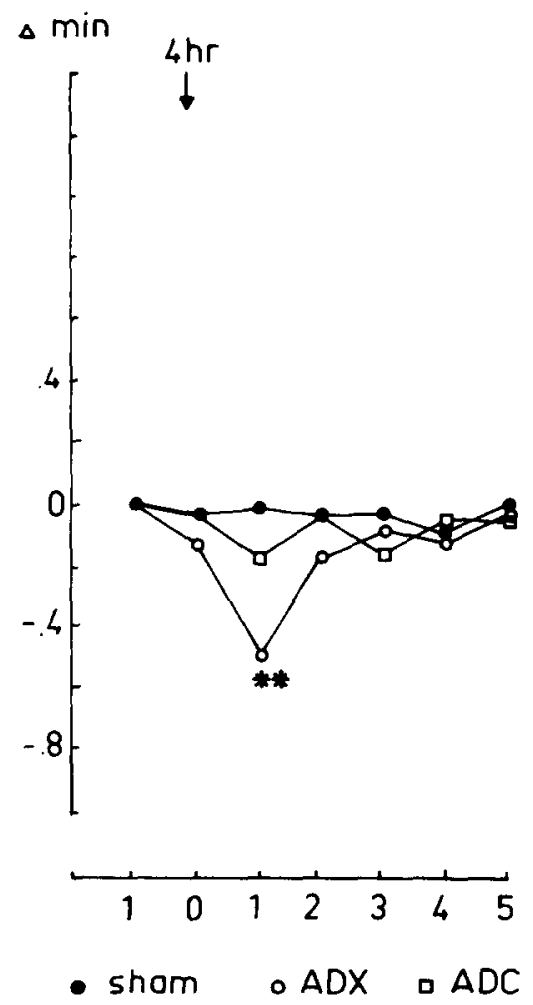

BD

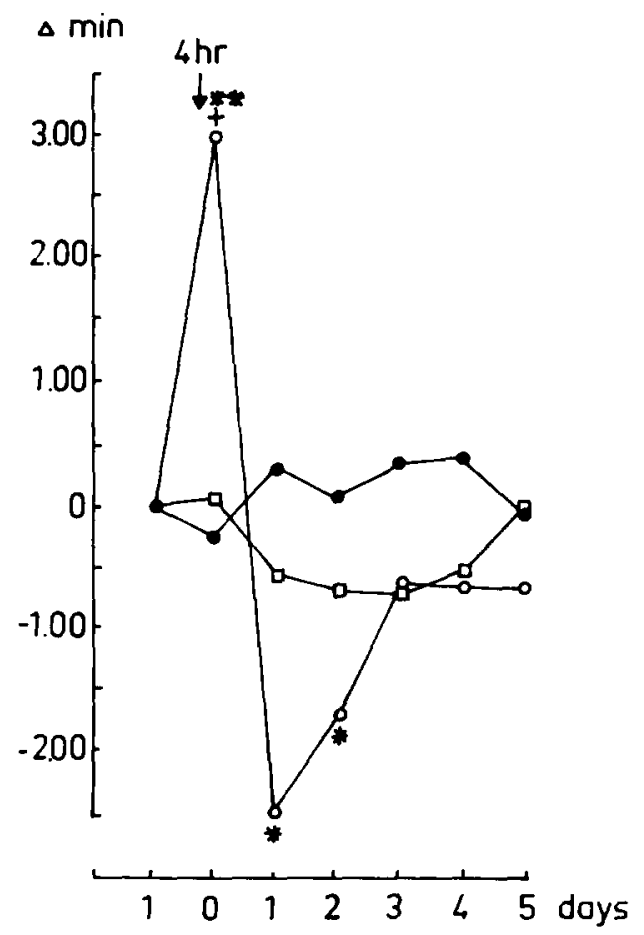

Fig. 2. Effect of $4 \mathrm{~h}$ adrenalectomy (ADX; $\bigcirc-0$ ), adrenalectomy plus corticosterone substitution (ADC; $\square-\square$ ) or sham-operation (sham; -1 ) on the duration of the after-discharge (AD) and of the behavioural depression (BD) in hippocampal kindled rats. Each point represents the mean difference score. Statistical significance of differences between sham and ADX rats is shown by asterisks: ${ }^{*} P<0.05 ;{ }^{* *} P<0.01$. The symbol + depicts the statistical difference between ADX and ADC rats: ${ }^{+} P<$ 0.05 . 
der light ether anaesthesia, and corticosterone concentration was determined in the plasma by radioimmunoassay. The mean corticosterone levels $4 \mathrm{~h}$ after operation were $7.0 \pm 1.0 \mu \mathrm{g} / 100 \mathrm{ml}$ in the sham group, nearly below detection level in the ADX group, and $9.5 \pm 1.4 \mu \mathrm{g} / 100 \mathrm{ml}$ in the ADC group. Thus, the plasma corticosterone levels in the sham and ADX groups are very similar, showing that the corticosterone substitution regimen was appropriate. The results are presented in Fig. 2. The 4-h ADX and sham groups performed as in Experiment $1 \mathrm{~B}$. Shams did not significantly deviate from their baseline. While, at $4 \mathrm{~h}$, the ADX group exhibited an increased BD $(t=3.713, P<0.003)$, at one day a decreased $\mathrm{AD}$ and $\mathrm{BD}(\mathrm{AD}, t=-3.797, P<0.007$; $\mathrm{BD}, t=-2.443, P<0.01)$, at two days a normal AD and decreased BD $(t=-2.437, P<0.021)$, and at 3 days normal $\mathrm{AD}$ and $\mathrm{BD}$. The $\mathrm{ADC}$ group did not show the increased $B D$ at $4 \mathrm{~h}$, and their performance was not significantly different from the shams. Their $\mathrm{AD}$ and $\mathrm{BD}$ showed a moderate reduction at one day post-ADX, but was not significantly different from the sham group's performance. According to pilot experiments one may expect at one day comparable undetectable plasma corticosterone levels both in ADX and ADC rats.

The present findings suggest that removal of the adrenal cortex in the rat is followed by complex but short-term changes in the electrical and behavioural consequences of hippocampal kindling. There were short-term effects of ADX on hippocampal kindled seizures lasting from $4 \mathrm{~h}$ to 3 days post-ADX. First an effect of $1 \mathrm{~h}$ was observed in both ADX and sham groups. Then an ADX-induced increase in $B D$ at $4 \mathrm{~h}$, and subsequently at $8 \mathrm{~h}$ and lasting 1-3 days, there is an $\mathrm{ADX}$-induced reduction in $\mathrm{AD}$ and $\mathrm{BD}$. The changes caused by adrenalectomy could be normalized by corticosterone substitution.

At $1 \mathrm{~h}$, both ADX and sham groups exhibited fewer seizures and a decreased duration of $A D$ and $B D$. This 1 -h effect is probably a generalized stress effect. It is, however, not due to the ether alone (or ether-induced increase in corticosterone) as ether administration alone, $1 \mathrm{~h}$ before stimulation, had no effect on the kindled seizure (unpublished observation). Possibly it concerns the stress evoked by surgical procedure. Stress-induced protection against convulsions has also been observed by Oliverio et al. ${ }^{14}$. They found that mice subjected to immobilization stress were protected against ECS-induced seizures. Whether classical 'stress-hormones' (corticosteroids and catecholamines) or pituitary and/or brain-born peptides are involved in depression in the kindlinginduced $A D$ and $B D$ after surgeries remains to be determined.

The $\mathrm{BD}$ exhibits greatly variable responses (large increases or decreases in duration) depending upon the amount of time that has elapsed following ADX. Thus, the BD would appear to be extremely sensitive to ADX. However, the 1-h and 1-3-day decreased $\mathrm{BD}$ can be accounted for by the absence of $\mathrm{AD}$ or decreased $\mathrm{AD}$; i.e. when there is no convulsion there is no $\mathrm{BD}$, when a convulsion is mild the $\mathrm{BD}$ is usually short. That leaves the 4-h (and sometimes 8-h) increase in BD to be explained. It is not due to the operation since sham-operated rats, which do have convulsions, exhibit $\mathrm{BD}$ of normal length. One possibility is the absence of corticosterone. This hypothesis is supported by the finding that corticosterone replacement therapy, which produced physiological levels of corticosterone in the plasma of ADX rats, prevented an increase in the duration of BD at $4 \mathrm{~h}$. Thus, we postulate that corticosterone is important for the expression of seizure behaviour.

Of particular note is the fact that this corticosterone substitution, at the time of ADX, also abolished the consequence of $\mathrm{ADX}$ on $\mathrm{AD}$ and $\mathrm{BD}$ on the following days. It is possible that this is, in fact, caused by the action of corticosterone during the 4-h test; i.e. abolishing the changes in seizure pattern reinstates the preoperative seizure levels. This explanation is not likely as normal seizures can occur after a period of abnormal seizure behaviour. For example, the sham group exhibited markedly decreased $\mathrm{AD}$ and $\mathrm{BD}$ at $1 \mathrm{~h}$, but normal $\mathrm{AD}$ and $\mathrm{BD}$ at one day. The normalization is not due to the presence of corticosterone at day 1 , as there is no corticosterone in the plasma of substituted rats $24 \mathrm{~h}$ post-corticosterone replacement therapy (unpublished observation). It is more likely that the reinstatement is due to some secondary action of corticosterone.

Dana et al. ${ }^{4}$ have also reported an ADX-sensitive, corticosterone-specific change in an electrically stimulated modulation of hippocampal function. They found that ADX rats failed to develop long-term potentiation (LTP) following high-frequency stimula- 
tion of the perforant path. Further, they also found that corticosterone substitution restored the ability to develop LTP. No long-term effect, 4-14 days, was found. This agrees with the findings of McIntyre ${ }^{13}$ who also found no effects of ADX on seizures elicited from amygdala kindled rats that had been adrenalectomized for one week. Furthermore, behavioural alterations have been observed shortly following ADX in the rat. These deficits could be normalized by corticosterone in agreement with the specificity of glucocorticoid receptors in the brain ${ }^{1,2}$.

In conclusion, a disruption in the pituitary-adrenal-hippocampal neuroendocrine system can disrupt hippocampal kindled seizures often resulting in milder seizures. The data indirectly imply that corticosterone receptors, in the hippocampus, may be involved in the maintenance of the kindled seizure, as the $A D$ and $B D$ are disrupted by removal of endogenous corticosterone and reinstated by a physiological dose of corticosterone. However, the animal can adapt to a change in its hormonal milieu after ADX as

1 Bohus, B. and de Kloet, E. R., Adrenal steroids and extinction behavior: antagonism by progesterone, deoxycorticosterone, and dexamethasone of a specific effect of corticosterone, Life Sci., 28 (1981) 433-440.

2 Bohus, B., de Kloet, E. R. and Veldhuis, H. D., Adrenal steroids and behavioral adaptation: relationship to brain corticosterone receptors. In D. Ganten and D. Pfaff (Eds.), Current Topics in Neuroendocrinology, Vol. 2, Adrenal Action on the Brain, Springer-Verlag, Berlin, 1982, pp. 107-148

3 Cottrell, G. A., Nyakas, C., Bohus, B. and de Wied, D., ACTH and MSH reduce the after-discharge and behavioral depression following kindling. In E. Endröczi, D. de Wied, L. Angelucci and U. Scapagnini (Eds.), Integrative Neurohumoral Mechanisms, Elsevier, Amsterdam, 1983, pp. 91-97.

4 Dana, R. C., Gerren, R. A., Sternberg, D. B., Martinez, Jr., J. L., Hall, J., Stansbury, N. A. and Weinberger, N. M., Long-term potentiation is impaired by adrenalectomy and restored by corticosterone, Soc. Neurosci. Abstr., 8 (1982) 316.

5 Endröczi, E., Brainstem and hypothalamic substrate of motivated behaviour. In K. Lissák (Ed.), Recent Developments of Neurobiology in Hungary, Vol. 2, Results in Neurophysiology, Neuroendocrinology, Neuropharmacology and Behaviour, Akademiai Kiado, Budapest, 1969, pp. 27-49.

6 Feldman, S., The interaction of neural and endocrine factors regulating hypothalamic activity. In A. Brodish and E. S. Redgate (Eds.), Brain-Pituitary-Adrenal Interrelationships, Karger, Basel, 1973, pp. 224-238.

7 Goddard, G. V., McIntyre, D. C. and Leech, C. L., A permanent change in brain functions resulting from daily elec- kindled seizures return to baseline with time. It remains to be shown whether the adaptation (reinstatement) is indeed due to an 'escape' from hormonal control or whether other neuroendocrine mechanisms (of peptidergic nature) compensate for the absence of adrenal cortical hormones.

G. A. Cottrell, presently at the Department of Pharmacology, Dalhousie University, Halifax, Canada, was supported by a post-doctoral fellowship of the Canadian Medical Research Council. C. Nyakas was on leave of absence from the Department of Experimental and Clinical Laboratory Investigations, Postgraduate Medical School, Budapest, Hungary. These studies were supported in part by the Stichting Farmacologisch Studiefonds Utrecht and European Training Programme in Brain and Behaviour Research Twinning Grant. The valuable technical assistance by Mrs. T. H. A. M. Voorhuis-Rongen is greatly acknowledged. The secretarial aid of Mrs. Joke Poelstra-Hiddinga is also acknowledged.

trical stimulation, Exp. Neurol., 25 (1969) 295-330.

8 Halmi, L., Bohus, B., Frey, Z. and Endröczi, E., Direct metyrapone effect on the central nervous system, Endocrinologie, 57 (1970) 139-141.

9 Heuser, G. and Eidelberg, E., Steroid-induced convulsions in experimental animals, Endocrinology, 69 (1961) 915.

10 Hull, C. H. and Nie, N. H., SPSS Uptake 7-9, McGraw Hill, New York, 1981.

11 McEwen, B. S., Weiss, J. M. and Schwartz, L. S., Uptake of corticosterone by rat brain and its concentration by certain limbic structures, Brain Research, 16 (1969) 227-241.

12 McEwen, B. S., Glucocorticoids and hippocampus: receptors in search of a function. In D. Ganten and D. Pfaff (Eds.), Current Topics in Neuroendocrinology, Vol. 2, Adrenal Actions on Brain, Springer-Verlag, Berlin, 1982, pp. 1-22.

13 McIntyre, D. C., Adrenalectomy: protection from kindled convulsion induced amnesia in rats, Physiol. Behav., 17 (1976) 789-795.

14 Oliverio, E., Castellano, C. and Puglisi-Allegra, S., Anticonvulsant effects of stress: role of endogenous opioids, Brain Research, in press.

15 Veldhuis, H. D. and de Kloet, E. R., The adrenal receptor system in rat hippocampus. In E. Endröczi, D. de Wied, L. Angelucci and U. Scapagnini (Eds.), Integrative Neurohumoral Mechanisms, Elsevier, Amsterdam, 1983, pp. $157-164$.

16 Woodbury, D. M., Relation between the adrenal cortex and the central nervous system, Pharmacol. Rev., 10 (1958) 275-345.

17 Woodbury, D. M., Role of pharmacological factors in the evaluation of anticonvulsive drugs, Epilepsia, 10 (1969) 121-144. 